\title{
Influence of Demography, Religiosity and Porting Behaviour on Switching Behaviour of Mobile Subscribers: Evidence from A Developing Country
}

\author{
Simon Gyasi Nimako ${ }^{1} \&$ Robert K. Nyame ${ }^{1}$ \\ ${ }^{1}$ University of Education, Winneba, Ghana \\ Correspondence: Simon Gyasi Nimako, University of Education, Winneba, Ghana. E-mail: \\ sim.ekomerce@gmail.com
}

Received: April 11, 2015

Accepted: May 4, 2015

Online Published: June 20, 2015

doi:10.5539/ijbm.v10n7p158

URL: http://dx.doi.org/10.5539/ijbm.v10n7p158

\begin{abstract}
The paper examines the extent to which consumer demography, religiosity and porting behaviour predict consumer switching behaviour (CSB) in the context of mobile subscribers from an emerging market perspective. Drawing from relevant literature, a predictive model was developed to test the influence of demography, religiosity and porting behaviour on CSB. Empirical data were collected through a cross-sectional survey design involving 736 mobile subscribers from six telecoms in Ghana. Data were analysed using binary logistics regression to test the proposed model. The results indicate that the effect of some demographics (age, income and length of relationship) and porting behaviour were statistically significant in predicting mobile subscribers' switching behaviour, while other demographics (gender, education, marital status and phone use experience) and religiosity did not contribute to predicting switching behaviour of mobile subscribers in Ghana. The theoretical and managerial implications of this study are discussed. The limitations of this study offer avenues for future research.
\end{abstract}

Keywords: switching, telecom services, demography, porting behaviour, religiosity, logistics regression

\section{Introduction}

Over the past two decades, scholars, marketers, business practitioners and educators have shown much interest not only in attracting profitable customers but also in preventing them from switching to competitors (Bansal, Taylor, \& James, 2005; Keaveney, 1995). Consequently, service providers try to understand factors that cause consumers to switch in order to prevent complete switching. From marketing literature the most widely studied determinants of consumer switching are factors that can be grouped as push, pull and mooring factors (Bansal et al., 2005; Clemes, Gan, \& Zheng, 2007; Ye \& Potter, 2011; Hou, Chern, Chen, \& Chen, 2011; Hsieh, Hsieh, Chiu, \& Feng, 2012; Zhang, Cheung, \& Lee, 2012). Very little research attention has been devoted to exploring other switching behaviour predictors such as demography and relationship characteristics.

Consumer characteristics such as demographic, cultural, personality and religiosity, and socio-economic variables can provide useful insights to marketers towards understanding consumer behaviour towards service products in general and consumer switching behaviour (CSB) in particular (Keaveney \& Parthasarathy, 2001; Ranganathan, Seo \& Babad, 2006). To begin with, demographic analysis of consumers could provide strong basis for marketing segmentation purposes. It also provides justifications for product development and customisations agenda of manufacturing firms in emerging markets (Kotler \& Keller, 2012). Moreover, it provides a means of building theories about consumer behaviour. It helps to predict consumers' behaviour and therefore provides indicators for developing effective marketing segmentation and business strategies in competitive markets. In advertising and other mass communication settings, consumer demographics play key role in helping to shape the type of message and communication media to achieve desired results.

Conducting business in electronic service environment such as mobile telecommunication services industry (MTI) presents its own uniqueness and implications for consumer switching. In MT1 environment, partial switching has become mandatory by means of mobile number portability adoption (MNP) by mobile subscribers (Buehler \& Haucap, 2004; Nimako, Ntim, \& Mensah, 2014). However, encouraging total switching can be detrimental to service providers, especially in competitive industry. Given the critical role that consumer demography, religiosity and porting behaviour can play in consumer and business markets, this paper makes an attempt to provide an 
empirical analysis of the role these factors play in predicting mobile subscribers' switching behaviour, especially from a developing country perspective, using Ghana mobile telecom industry (GMTI) as the research context.

The problem of this study stems from two areas. First is the limitations of existing marketing and CSB research and, second, the need to develop evidence-based marketing strategies using consumers' background characteristics in consumer markets. In the marketing and CSB literature, past studies have made attempts to provide empirical evidence on the influence of demographic and cultural factors that influence CSB (e.g., Keaveney \& Parthasarathy, 2001; Ranganathan et al., 2006; Lee, Kim, Lee, \& Park, 2006; Lopez, Redondo, \& Olivan, 2006; Shin \& Kim, 2008). However, very little attempt has been given to studying the effect of demographic and porting behaviour on CSB in developing economy contexts in general, and mobile subscribers in particular (e.g., Effah-Bediako, Deh, \& Asuamah, 2013; Shin \& Kim, 2008).

Moreover, relatively few studies have examined the effect of consumer religiosity on CSB in different service contexts (Yousaf \& Malik, 2013). Therefore, recent studies have called upon future research to further our theoretical understanding regarding the role of consumer religion and religiosity in CSB (Choi, 2010; Choi et al., 2013). Furthermore, with the introduction of MNP in many mobile telecom industries in the world, porting behaviour, described as consumer adoption and non-adoption of MNP, has become an important factor that appears to have considerable influence in determining consumer switching decisions (Buehler \& Haucap, 2004; Nimako et al., 2014; Shin \& Kim, 2007, 2008). This is particularly important given that the adoption of MNP by consumers indicates a partial switching situation that can influence a decision to switch carriers completely. Empirical studies that examine the effect of demographic and religious factors in CSB in a single study is very rare. Consequently, studying the effect of consumer characteristics such as porting behaviour, demography and religiosity can enhance scholars' and practitioners' understanding of the usefulness of these consumer characteristics in the prediction of mobile subscribers' switching behaviour, especially in competitive markets in developing countries like Ghana.

In view of the above, this paper focuses on examining the extent to which consumer demography, religiosity and porting behaviour combine to predict mobile subscribers' switching behaviour in emerging market perspective. The main theoretical contribution of this paper lies in providing theoretical support for understanding the extent to which consumer demography, religiosity and porting behaviour can predict CSB in emerging economy contexts, which is under-researched. Its managerial contribution emerges from the strategies management can develop based on the findings in order to survive the keen competition in MTI in developing countries, which is characteristically different from developed economies in many respects (Kuada, 2010).

The paper continues with relevant literature review and development of conceptual framework and hypothesis. This is followed by a description of the research methodology and data analysis. It then presents results, discussion of findings, and theoretical and practical implications of the research. It ends with discussion of research limitations, directions for further research and conclusion.

\section{Literature Review}

\subsection{Defining Switching Behaviour}

According to Nimako (2012), "Consumer switching behaviour is the process by which a consumer abandons his/her relationship with a current service/product provider and replaces it with a competitor partially or entirely for a given time period." (p. 68). This comprehensive definition suggests several dimensions and typologies of the CSB phenomenon, notably, the fact that switching is a process and could be partial or total. In many research contexts, the idea of switching represents a complete or total switch from one service provider to another (Nimako, 2012). In the mobile telecom service context, switching through the help of MNP policy represents a partial switching phenomenon since subscribers who port their mobile numbers to competitor networks still retain their current service providers. Switching is complete when consumers terminates an existing relationship with a mobile carrier and substitutes it for a competitor (Nimako, 2012; Njite, Kim, \& Kim, 2008). Thus, complete switching behaviour emphasizes two sides of the switching process, a switch from and a switch to dimensions. The conceptual framework for this study conceptualizes switching behavour as a complete or total switch, where a consumer has actually switched to a new service provider completely, and not through MNP adoption.

\subsection{Consumer Demographics and Switching Behaviour}

Our understanding of the influence of consumer demography and religiosity on consumer behaviour in general and switching behaviour in particular has been enhanced by earlier studies in the information systems and wireless network environments (e.g., Chen \& Hitt, 2002; Dholakia \& Uusitalo, 2002; Gilbert, Lee-Kelley, \& Barton, 2003; Keaveney \& Parthasarathy, 2001). 


\subsection{Religiosity and Consumer Switching}

Generally, current research has established that religiosity can affect consumer purchasing, switching behaviour and other behavioural intentions (e.g., Choi, 2010, Choi et al., 2013; Moschis \& Ong, 2011; Yousaf \& Malik, 2013). In a study in Pakistan, Yousaf \& Malik (2013) found that consumer behaviour varies with the level of involvement and the degree of religiosity. For high involvement product category, the highly religious group was found to be less recreational, fashion conscious and impulsive in their shopping orientations. In the case of the low involvement product category, religiosity negatively influenced the brand consciousness of consumers. In Malaysia, Moschis and Ong (2011) found positive effects of religiosity on well-being but showed that this influence were different across the three main ethnic subcultures of Malaysia (Malays, Indians, and Chinese).

Moreover, Choi (2010) found that Korean consumers reporting high levels of religiosity were less likely to engage in product purchase and store-switching behaviours than those reporting lower levels of religiosity. Also, consumers reporting high levels of religiosity are also less likely to engage in product purchase switching behaviour than non-religious affiliated consumers (i.e., no religiosity consumers). More recently, Choi et al. (2013) in a comparative study of consumers in Korea and USA, found that religiosity, expressed as the importance of religious beliefs in one's life, can be a factor that influences CSB, but religious affiliation was not a good predictor of CSB. Studies such as Choi (2010) and Choi et al. (2013) have called on future research to examine the influence of religiosity in new research context.

From the above discussion, although these previous studies have highlighted the impact of demographics and religiosity on switching intentions and behaviour, research in these areas have received relatively little attention, especially in developing country mobile markets. Relatively few studies to date have identified which customer characteristics might be effective in predicting CSB in developing country mobile markets (e.g., Effah-Bediako et al., 2013; Moschis \& Ong, 2011; Yousaf \& Malik, 2013). This study hopes to contribute to filling this gap in the literature.

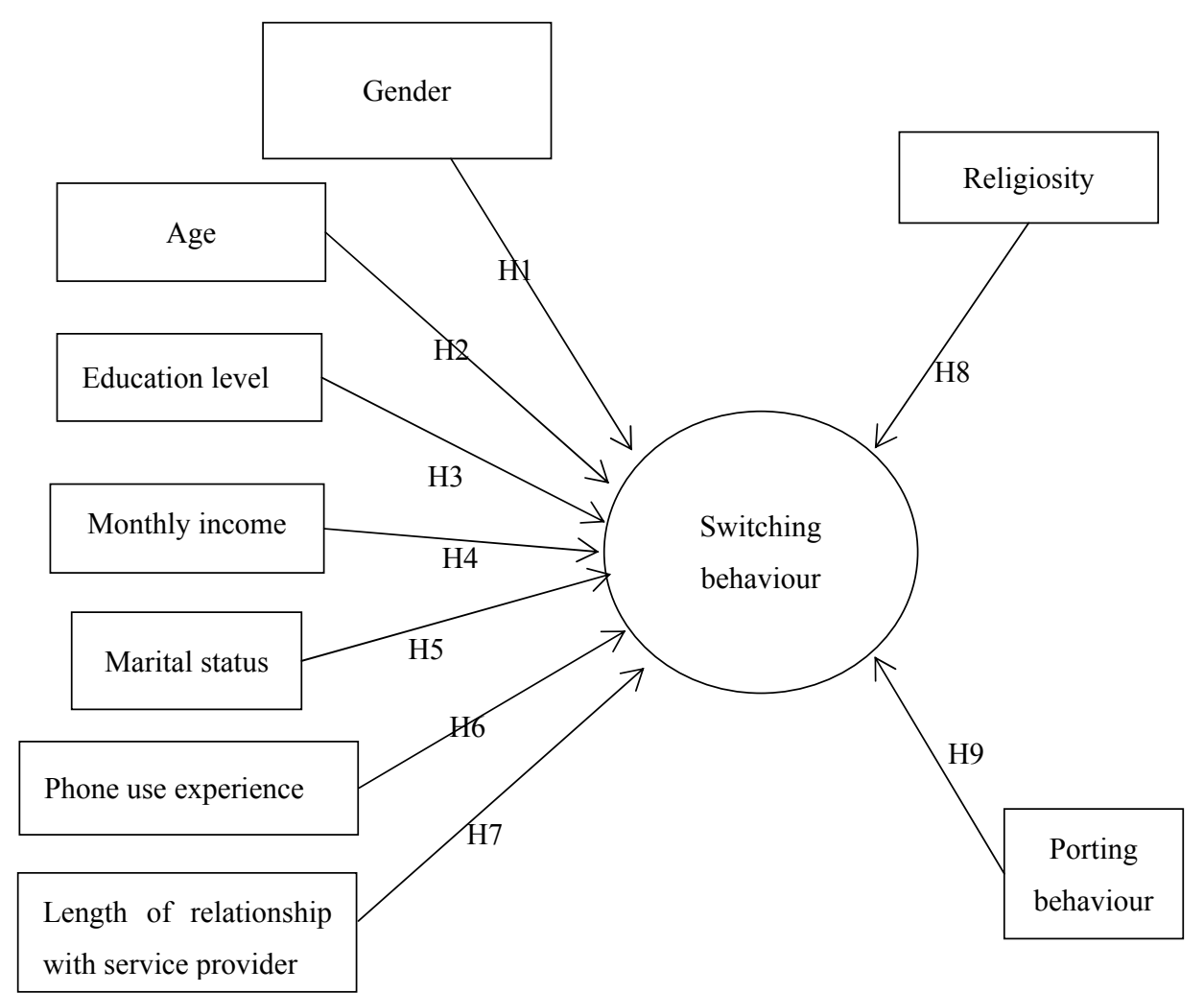

Figure 1. Conceptual framework and hypothesis

\subsubsection{Gender}

Several studies have shown that female customers tend to experience higher levels of anxiety than males in using technologies (Gilbert, Lee-Kelley, \& Barton, 2003). This anxiety is likely to discourage females from switching 
from one carrier to another. Ranganathan, Seo and Babad (2006) show that males are more prone to switching carriers, and age is negatively linked to switching. Effah-Bediako et al. (2013) also found that in telecom service context, more males switch their service providers than females. However, Shin and Kim (2008) found that gender may not affect subscribers' decisions on switching. These contradictory empirical evidence imply that the role of gender in switching behaviour might be different for specific research contexts and consumers. In the midst of these contradictions, we investigate the role of gender on switching behaviour and hypothesize that:

H1: Gender will significantly predict actual switching behaviour. Specifically, male mobile subscribers are more likely to switch mobile network service providers than female mobile subscribers.

\subsubsection{Age}

Carroll, Howard, Peck and Murphy (2002) found that young mobile users use mobile services to satisfy their social and leisure needs, reinforce group identity, and add value to their lifestyles. Shin and Kim (2008) found that age has a stronger association with switching compared to education, and that younger subscribers are more likely to switch mobile carriers than older subscribers. However, the results of Effah-Bediako et al. (2013) show that age has no statistical significant effect on switching behaviour of consumers, contradicting previous findings that age influences the switching behaviour of consumers of mobile service (e.g. Dholakia \& Uusitalo, 2002; Shin \& Kim, 2008). Therefore, the present study hypothesizes that:

H2: Age will significantly predict actual switching behaviour. Specifically, younger mobile subscribers are more likely to switch mobile network service providers than older mobile subscribers.

\subsubsection{Education}

Previous studies (e.g., Dholakia \& Uusitalo, 2002; Keaveney \& Parthasarathy, 2001; Shin \& Kim; 2008; Ranganathan et al., 2006) have found that education level is positively linked to switching. In particular, Shin \& Kim (2008) found that subscribers with higher levels of education are relatively more prone to switching mobile carriers than those with lower education levels. Carroll et al. (2002) also found that more educated people view mobile devices as lifestyle-related tools as well as task-oriented technologies. This attitudinal shift might influence people's switching intentions as well. It is expected that more educated consumers will be more enlightened about their rights, have more knowledge of MNP and be more sensitive to competitors' offers, and know when and how to switch than less educated mobile subscribers. This means more educated consumers are able to switch more than less educated mobile subscribers. This leads to the hypothesis that:

H3: Education will significantly predict actual switching behaviour. Specifically, mobile subscribers with high levels of education are more likely to switch mobile network service providers than those with low levels of education.

\subsubsection{Income}

Effah-Bediako et al. (2013) claims that family income is a moderating demographic variable in consumer switching. This appears inconsistent with that of earlier researchers (e.g. Dholakia \& Uusitalo, 2002; Ranganathan et al., 2006), who found family income as significant predictor of switching behaviour of mobile subscribers. Relatively, consumers who earn more can bear the financial cost of switching and therefore are more likely to switch when dissatisfied with current service provider than lower income earners who may perceive the monetary cost involved in switching as a barrier to switching. Therefore, this leads to the hypothesis that:

H4: Consumer income will significantly predict actual switching behaviour. Specifically, mobile subscribers with high levels of income are more likely to switch mobile network service providers than those with low levels of income.

\subsubsection{Marital Status}

Dholakia \& Uusitalo (2002) maintained that there is significant relationships between consumers' family composition and their online and offline store switching behaviour. Generally, married consumers appear more responsible and are more likely to make thoughtful considerations before switching than unmarried ones. There is very limited research that examines the influence of marital status on consumer switching. Families that subscribe to a mobile network service provider may find it difficult switching than unmarried consumers who do not have such family and marital ties. Unmarried consumer may also be easily influenced by social and referent groups to make impulsive switching behaviour. This study provides empirical evidence on the influence of marital status on switching behaviour, and hypothesizes that:

H5: Marital status will significantly predict actual switching behaviour. Specifically, married mobile subscribers are more likely to switch mobile network service providers than those who are not married. 


\subsubsection{Phone Use Experience}

Length of experience with a service provider (relationship length) and the length of experience with general phone use are two related but different things. While the length of time customers have been in relationship with a service provider might influence switching decision (Lopez et al., 2006), their general experience with phone use may not directly or necessarily influence service provider switching decisions. This is because the mobile handset might be purchased differently from the mobile network service subscription. Even though some service providers in some MTI contexts provide customised mobile handset, this might not necessarily induce consumer switching. Therefore, this study hypothesizes that:

H6: Mobile phone use experience will not significantly predict actual switching behaviour. Specifically, mobile subscribers with more years of mobile phone use experiences are not more likely to switch mobile network service providers than those with less experience in mobile phone use.

\subsubsection{Relationship Length}

Lopez et al. (2006) found that relationship length is a key predictor of consumer switching behaviour and that consumers who stay in longer relationship with current service providers are also less likely to switch to a new one. As consumers stay longer in relationship with service providers, they are able to use the firm's offering more, develop attachment (Batra et al., 2012; Carroll \& Ahuvia, 2006; Sheth \& Parvatiyar, 1995) and love for service provider brands and become committed to service brands (Bansal \& Taylor, 1999; Lopez et al., 2006). Thus, length of relationship experienced with a service provider can influence consumers to either stay or leave. Therefore, it is hypothesized that:

H7: Relationship length experience will significantly predict actual switching behaviour. Specifically, mobile subscribers with longer relationship experience are more likely to switch mobile network service providers than those with shorter relationship with service providers.

\subsubsection{Religiosity}

Religiosity can be defined as the importance of religious beliefs in one's life (Choi et al., 2013). Choi (2010) found that Korean consumers reporting high levels of religiosity were less likely to engage in product purchase and store-switching behaviours than those reporting lower levels of religiosity. Also, consumers reporting high levels of religiosity are also less likely to engage in product purchase switching behaviour than non-religious affiliated consumers (i.e., no religiosity consumers). Choi et al. (2013) also suggest that, comparatively, the level of religiosity of consumers in Korea and USA influenced CSB. In many developing countries like Ghana, as far back as ancient times, high levels of religiosity appears to dominate the general life of the people (Anderson, 2013). According to a report by the Global Index of Religiosity and Atheism (2012, p. 4), Ghana leads on religiosity in the world with $96 \%$ of people in Ghana claiming to be religious. Thus, religiosity of mobile subscribers in Ghana may influence their CSB. This leads to the hypothesis that:

H8: Religiosity will significantly predict actual switching behaviour. Specifically, mobile subscribers with high levels of religiosity are more likely to switch mobile network service providers than those with low levels of religiosity.

\subsubsection{Porting Behaviour}

Porting behaviour is defined as the extent to which mobile subscribers port their mobile numbers to another network or not (Nimako et al., 2014). MNP adoption behaviour could influence consumers' switching intention and even actual switching behaviour (Buehler \& Haucap, 2004; Lee et al., 2004; Shin \& Kim, 2008). But the extent to which MNP is inducing actual switching behaviour in general and GMTI in particular, remains an important gap in the extant literature on CSB and MNP adoption. Although the relationship between MNP adoption and actual switching appears to be a straight forward one, research into this area can provide further insight for scholars and practitioners.

Consumer adoption of MNP is expected to facilitate consumer switching. But conceptually, this would imply that porting one's mobile number itself is a partial switching phenomenon that allows consumers to switch while retaining their existing mobile numbers. This situation might not provide the incentive to consumers to actually switch completely to a new service provider and terminate relationship with an existing service provider due to lock-in other MNP switching behaviours and MNP lock-in strategies by service providers (Shin \& Kim, 2007, 2008). This leads to the hypothesis that:

H9: Porting behaviour will significantly predict actual switching behaviour. Specifically, mobile subscribers who port to another mobile service provider's network are more likely to switch current mobile network than those who 
have not ported (non-adopters or non-porters).

\section{Methodology}

\subsection{Population and Sampling}

The population consisted of 26,591,124 individual subscribers as of April, 2013 (National Communication Authority-NCA, 2013) from the six mobile telecommunication operators in Ghana, operating under these brand names: MTN Ghana, Vodafone Ghana, Airtel Ghana, Tigo, Expresso and Glo Ghana. The appropriate sample size was estimated using a formula proposed by Yamane (1967), which yielded a minimum sample size of 400. In order to collect data of high quality that reflect customers' opinion and have quality of good representativeness, a survey was conducted from a cross-section of mobile telecom subscribers in the country in July 2013. The survey yielded a usable 736 questionnaires for data analysis.

\subsection{Research Instrument}

The study was part of a larger study that used a self-administered, structured questionnaire, which was pre-tested to a sample of twenty (20) customers. After adjustments were made based on the pre-test to get a more effective instrument, the instrument was finally administered to the target population through personal contact. Since this paper focuses on the influence of demography, religiosity and porting behaviour on switching behaviour, only the relevant items are presented in the present study. The respondents' demographic data included gender, age, education, income, marital status, phone use experience, relationship length, whether customer has ported their mobile number or not, and whether they had switched or not in the last two years. Religiosity, defined as the importance of religious beliefs in one's life, was measured on a five-point Likert scale ranging from strongly disagree to strongly agree, coded 1 to 5 respectively based on previous research (Choi, 2010; Choi et al., 2013). All demographic variables used in this study are shown in Table 1.

\subsection{Data analysis Method}

A Binary logistics regression analysis was conducted to assess the influence of background data on switching behaviour since the variables involved a categorical dependent variable, switching behaviour, categorised as switchers (for yes responses) and non-switchers (for no responses). The logistic regression was chosen because of its soft non-parametric distributional assumptions (Hair, Black, Babin, \& Anderson, 2010). All tests were conducted using a significance value of 0.05 .

\section{Results}

\subsection{Respondents' Background Characteristics}

The characteristics of respondents are summarised in Table 1 . In terms of gender, $67.7 \%$ of the respondents were males and $32.3 \%$ were females. $20.7 \%$ of the respondents were below 25 years, $67.3 \%$ of them were within the ages of $25-36$ years, $11.4 \%$ were between 37 and 50 years, and $0.6 \%$ were 51 years and above. This implies that majority of them were in the economically active population.

All respondents were educated with about $58.6 \%$ of them having tertiary level of education, while about $5 \%$ and $33.4 \%$ had Senior High School (SHS) and post-SHS education respectively. Three per cent had other forms of education. In terms of income, $49.6 \%$ of respondents earned monthly income up to US\$ 250 , while $31.7 \%$ earned between US\$ 250 and US\$ 500, about 6.5\% earned monthly income above US\$ $500.12 .2 \%$ of the respondents were non-income earners. This indicates that most of the respondents earned considerably low incomes. This is to be expected because, generally, Ghana is considered a lower income country (The World Bank, 2013, http://data.worldbank.org/country/ghana), which is a typical characteristic of developing or emerging economies (Kuada, 2010).

In terms of marital status, $61.7 \%$ of the respondents were married, $36 \%$ were single (not married) and $2 \%$ of them were in other marital category. In terms of phone use experience, $9 \%$ of them had less than five years of experience, $56.1 \%$ of them had between 5 and 9 years of experience, $26 \%$ of them had between 15 and 19 years of experience and $8 \%$ of them had over 20 years of mobile network service use.

Generally, this indicates that most of respondents were considerably experienced in the use of phones and mobile network services. With respect to relationship length, 30.6\% of the respondents had been customers of a particular mobile network operator up to three years, $58.3 \%$ of the had quite longer relationship length of four to ten years, while $11.1 \%$ of them had the longest relationship length above 10 years with current service providers. Sixteen per cent of the respondents have ported their mobile phone numbers to other mobile telecom network while $84 \%$ of them have not yet ported their mobile phone numbers. 
Table 1. Respondents' background profile

\begin{tabular}{|c|c|c|c|}
\hline Variable & Category & Frequency & Percentage \\
\hline \multirow{2}{*}{ Gender } & Male & 498 & 67.7 \\
\hline & Female & 238 & 32.3 \\
\hline \multirow[t]{5}{*}{ Age } & Below 25 & 152 & 20.7 \\
\hline & $25-36$ & 495 & 67.3 \\
\hline & $37-50$ & 84 & 11.4 \\
\hline & $51+$ & 5 & 0.6 \\
\hline & SHS & 36 & 5 \\
\hline \multirow{3}{*}{ Education Level } & Post-SHS & 246 & 33.4 \\
\hline & Tertiary & 432 & 58.6 \\
\hline & Other & 22 & 3 \\
\hline \multirow[t]{4}{*}{ Monthly Income } & $<=\mathrm{US} \$ 250$ & 365 & 49.6 \\
\hline & US\$ $250-500$ & 233 & 31.7 \\
\hline & $>$ US\$ 500 & 48 & 6.5 \\
\hline & Non-income earners & 90 & 12 \\
\hline \multirow[t]{3}{*}{ Marital status } & Single (not married) & 454 & 61.7 \\
\hline & Married & 266 & 36.1 \\
\hline & Other & 16 & 2.2 \\
\hline \multirow[t]{4}{*}{ Phone use experience } & Less than 5 years & 67 & 9.1 \\
\hline & $5-9$ years & 413 & 56.1 \\
\hline & $15-19$ years & 194 & 26.4 \\
\hline & 20 years and above & 62 & 8.4 \\
\hline \multirow[t]{3}{*}{ Relationship length } & Up to 3 years & 225 & 30.6 \\
\hline & $4-10$ years & 429 & 58.3 \\
\hline & 10 years and above & 82 & 11.1 \\
\hline \multirow[t]{2}{*}{ Porting behaviour } & Porters & 120 & 16.3 \\
\hline & Non-porters & 616 & 83.7 \\
\hline \multirow[t]{2}{*}{ Switching behaviour } & Switchers (Yes) & 409 & 55.6 \\
\hline & Non-switchers (No) & 327 & 44.4 \\
\hline
\end{tabular}

Note. $\mathrm{n}=736$.

Source: Authors' field data, 2013.

\subsection{Results of Logistics Regression}

The purpose of this analysis is to determine the extent to which respondents' demographic, religious and porting characteristics predict their switching behaviour. To do this, the results of the binary logistic regression are presented in Tables 2, 3 and 4. In the binary regression model, there is one categorical dependent variable, switching behaviour, measured by a yes/no question item to determine switched/not switched subscribers. There are nine independent variables (gender, age, income, education, marital status, religiosity, porting behaviour, relationship length, and mobile phone use experience) that have been described already under respondents' background data.

First, the model goodness-of-fit is examined and then we proceed to examine the significance of the independent variables. Table 2 presents results of goodness-of-fit for the regression model. For the Omnibus Test of Model Coefficients Goodness-of-Fit Tests, the full model containing all the predictors was statistically significant, $\chi^{2}(9$, $\mathrm{N}=733)=47.977, \mathrm{p}<.001$ and the Hosmer-Lemeshow Goodness-of-Fit Test that requires an insignificant p-value also supports the model, $\chi^{2}(8, \mathrm{~N}=733)=7.531, \mathrm{p}>.05$. 
Table 2. Goodness-of-fit indices for binary regression model

\begin{tabular}{lllll}
\hline & Step 1 & Chi-square & df & Sig. \\
\hline Omnibus Tests of Model & Step & 47.977 & 9 & .000 \\
Coefficients & Block & 47.977 & 9 & .000 \\
& Model 1 & 47.977 & 9 & .000 \\
Hosmer and Lemeshow Test & & 7.531 & 8 & .481 \\
Model Summary & & & & \\
& Step 1 & -2 Log likelihood & Cox \& Snell R Square & Nagelkerke R Square \\
& & $963.180 \mathrm{a}$ & .063 & .084 \\
\hline
\end{tabular}

Moreover, from the classification table (Table 3), the sensitivity of the model represented in the percentage accuracy in classification is $62.5 \%$ indicating that the model is able to correctly classify $62.5 \%$ of cases overall, and specifically it is able to correctly classify $77.8 \%$ of consumers who did switch and $43.4 \%$ of cases that did not switch. The positive predictive value is $63.2 \%(318+185=503 ; 318 / 503 \times 100)$ indicating that out of the respondents predicted to have switched our model accurately picked $63 \%$ of them. The negative predictive value is $60.9 \%(91+142=233,142 / 233 \times 100)=60.9 \%$.

Table 3. Classification table

\begin{tabular}{|c|c|c|c|c|}
\hline \multicolumn{5}{|c|}{ Classification Table $^{\mathrm{a}}$} \\
\hline & \multirow{3}{*}{ Observed } & \multicolumn{3}{|c|}{ Predicted } \\
\hline & & \multicolumn{2}{|c|}{ Switched to other network } & Percentage \\
\hline & & YES & NO & Correct \\
\hline \multirow{3}{*}{ Step 1} & \multirow{2}{*}{ Switched to other network $\begin{array}{c}\text { YES } \\
\text { NO }\end{array}$} & 318 & 91 & 77.8 \\
\hline & & 185 & 142 & 43.4 \\
\hline & Overall Percentage & & & 62.5 \\
\hline
\end{tabular}

Note. a. The cut value is .500.

The overall predictive power of the model as displayed in Table 2 indicates Cox \& Snell R-square of 0.063 and Nagelkerke R-square of 0.084 , revealing that the predictive power of the model is relatively small $(8 \%)$. This is to be expected because background data could be a fraction of all the competing factors that affect switching decision process, which include many other push, pull and mooring switching factors (Bansal et al., 2005). Therefore, the proportion of the variance in switching behaviour predicted by the demographic and religious factors could be considered as reasonably good.

Table 4. Binary logistics: demography predictors of switching behaviour

\begin{tabular}{|c|c|c|c|c|c|c|c|c|c|}
\hline \multicolumn{10}{|c|}{ Variables in the Equation } \\
\hline & & \multirow{2}{*}{ Beta (B) } & \multirow{2}{*}{ S.E. } & \multirow{2}{*}{ Wald } & \multirow{2}{*}{ df } & \multirow{2}{*}{ Sig. } & \multicolumn{3}{|c|}{$\operatorname{Exp}(B) /$ Odds $95.0 \%$ C.I. for $\operatorname{EXP}(B)$} \\
\hline & & & & & & & Ratio & Lower & Upper \\
\hline \multirow{8}{*}{ Step $1^{\mathrm{a}}$} & Gender & .304 & .170 & 3.189 & 1 & .074 & .738 & .528 & 1.030 \\
\hline & Age & -.268 & .091 & 8.680 & 1 & $.003 *$ & 1.307 & 1.094 & 1.561 \\
\hline & Income & .244 & .086 & 8.104 & 1 & $.004 *$ & .783 & .662 & .927 \\
\hline & Education & .099 & .084 & 1.380 & 1 & .240 & .906 & .767 & 1.069 \\
\hline & Marital status & .167 & .168 & .977 & 1 & .323 & .847 & .609 & 1.178 \\
\hline & Porting behaviour & -.630 & .216 & 8.491 & 1 & $.004 *$ & 1.878 & 1.229 & 2.870 \\
\hline & Length of phone use & .109 & .105 & 1.086 & 1 & .297 & .897 & .730 & 1.101 \\
\hline & Length of relationship & -.249 & .072 & 11.871 & 1 & $.001 *$ & 1.282 & 1.113 & 1.477 \\
\hline
\end{tabular}




$\begin{array}{lllllllll}\text { Religiosity } & -.083 & .237 & .124 & 1 & .725 & 1.087 & .683 & 1.730 \\ \text { Constant } & 1.169 & .693 & 2.844 & 1 & .092 & .311 & & \end{array}$

Note. a. Variable(s) entered on step 1: Gender, Age, Income, Education, Marital status, Porting behaviour, Phone use experience, Length of relationship, Religiosity. Note: *p-value significant at 0.05 .

As earlier mentioned the whole model is statistically significant, $\chi^{2}(9, \mathrm{~N}=733)=47.977, \mathrm{p}<.001$, providing support for the fact that a model of demography, religiosity and porting behaviour could predict actual switching behaviour significantly in GMTI. For the significance of the predictors and hypotheses, as shown in Tables 4 and 5 respectively, four of the independent variables made an important statistically significant contribution to the model. These are Age $(p=0.003)$, Income $(p=0.004)$, length of relationship $(p=0.001)$ and porting behaviour $(\mathrm{p}=0.004)$, providing support for hypotheses $\mathrm{H} 2, \mathrm{H} 4, \mathrm{H} 8$ and $\mathrm{H} 9$ respectively. These are the major factors influencing whether a consumer will actually switch or not. Phone use experience did not significantly influence switching behaviour ( $\mathrm{p}>0.05$ ), supporting hypothesis H7. Gender, education, marital status and religiosity did not make significant impact on the decision to switch mobile network service provider, disproving hypotheses $\mathrm{H} 1, \mathrm{H} 3, \mathrm{H} 5$ and $\mathrm{H} 6$.

Among the significant factors, the strongest predictor of full switching is porting behaviour, recording a beta of -0.630 and an odds ratio of 1.878 . This indicates that porting behaviour negatively affects full switching behaviour (reduces the likelihood of full switching) or that respondents who port their mobile number(s) are less likely to fully switch to another mobile network than those who do not port. The odds ratio implies that for every porter, the odds of him/her fully switching decreases by 1.878 , all other factors held constant.

The next stronger predictor is age, recording a beta of -0.268 and an odds ratio of 1.307 . This also indicates that age negatively affects switching behaviour, and that the older a respondent is, the less likely he/she is to switch than younger respondents. The odds ratio implies that the likelihood of an older respondent switching decreases by 1.307 , all other factors being equal.

The third significant predictor of switching behaviour is length of a customer's relationship with service provider. It recorded a negative beta $(-0.249)$ and an odds ratio of 1.282 , indicating that the longer a respondent's relationship with a service provider the less likely he/she is to switch. Specifically, respondents with a longer relationship time with a mobile telecom service provider is about 1.282 less likely to switch than their respondents who have shorter relationship time, all other factors being equal.

Income is the fourth significant predictor of switching behaviour. It recorded a beta of 0.244 and an odds ratio of 0.783 , indicating that income positively influences switching behaviour or that the higher the income a respondent earns, the more likely he/she is to switch than those who earn lower incomes. The odds ratio implies that the likelihood of a higher income respondent switching increases a little higher than lower income respondents by 0.783 , all other factors held constant. A summary of the results of hypothesis testing are presented in Table 5 and Figure 2.

Table 5. Summary of results of hypotheses involving demographic influence on switching behaviour

\begin{tabular}{lll}
\hline Hypothesis & Predictors/Relationship & Remarks \\
\hline H1 & Gender predicts actual switching behaviour & Not supported \\
H2 & Age predicts actual switching behaviour & Supported \\
H3 & education predicts actual switching behaviour & Not supported \\
H4 & Income predicts actual switching behaviour & Supported \\
H5 & Marital status predicts switching behaviour & Not supported \\
H6 & Phone use experience will not affect switching beh. & Supported \\
H7 & Relationship length predicts switching beh. & Supported \\
H8 & Religiosity predicts actual switching behaviour & Not supported \\
H9 & Porting behaviour predicts actual switching behaviour & Supported \\
\hline
\end{tabular}




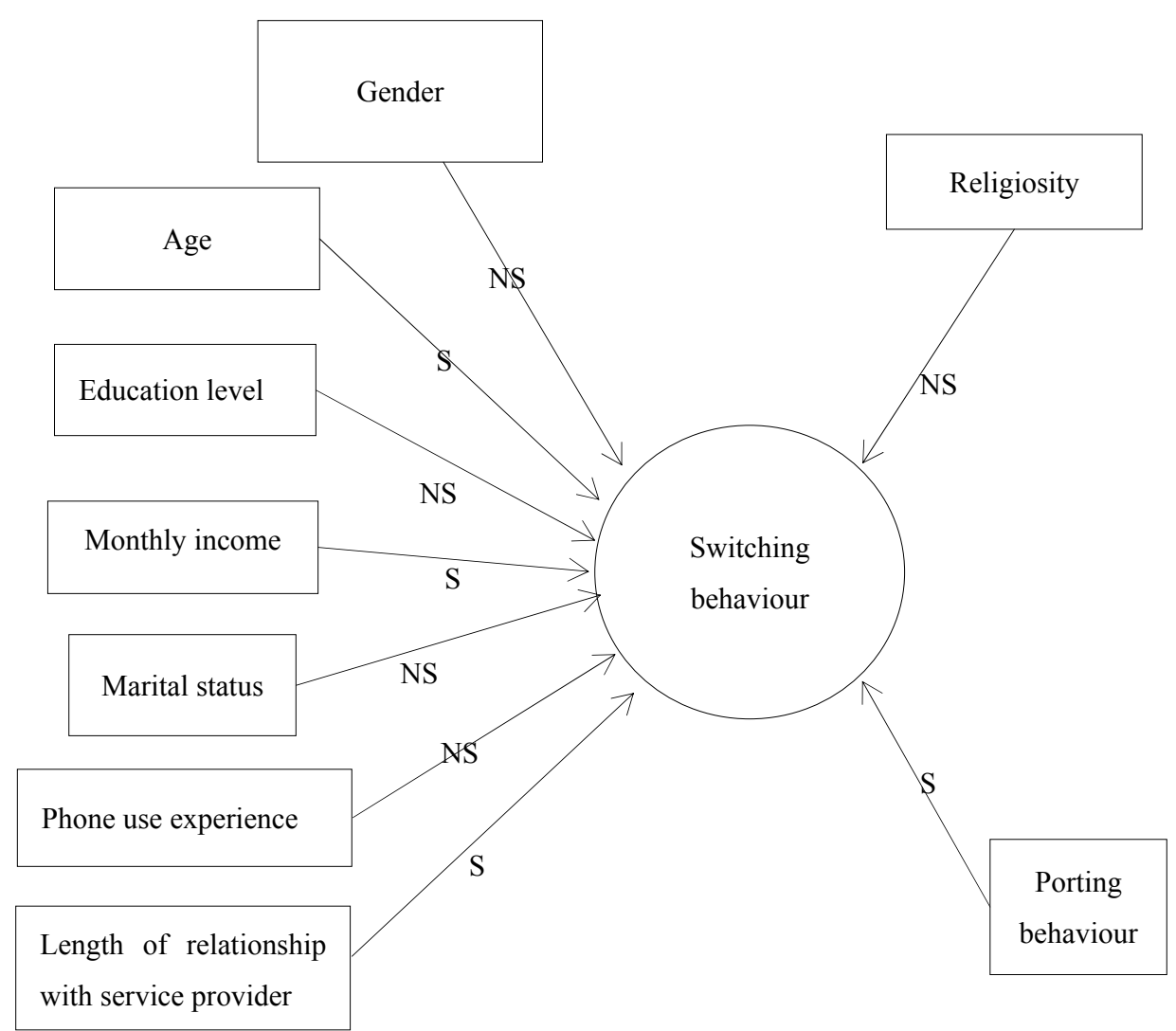

Figure 2. Summary of results of hypothesis testing

Notes. S-Significant, NS-Not Significant, all parameters are significant at 0.05 .

\section{Discussion}

The overarching purpose of this section of the study was to assess the extent to which demography, religiosity and porting behaviour predict CSB in GMTI. This is an attempt to fill the gap in the CSB literature regarding the role of demography, porting behaviour and religiosity in CSB in MTI in developing countries. These consumer characteristics studied in the present study are gender, age, education, income, marital status, mobile phone use experience, length of customer relationship, religiosity and porting behaviour. Generally, the present study found that consumer demography and porting behaviour can influence their switching behaviour. Specifically, four variables, age, income, porting behaviour and relationship length with firm significantly contributed to predicting total or complete switching behaviour in GMTI. However, according to the results, five other consumer background variables such as gender, education, religiosity, experience in phone use and marital status did not predict switching behaviour significantly.

Generally, these findings are consistent with some previous studies while contradicting others done in other mobile telecom industry contexts. First, this study found age as a significant predictor of switching behaviour among subscribers, supporting some past research (e.g. Shin \& Kim, 2008; Dholakia \& Uusitalo, 2002). The finding on age is inconsistent with those of (Effah-Bediako et al., 2013) who found that age has no statistical significant effect on switching behaviour and Ranganathan et al. (2006) who, though found age as significant switching predictor, states that age is negatively linked to switching. The present study found that older respondents are less likely to switch than younger respondents would, other things being equal, confirming Shin and Kim's (2008) study.

Second, this study found that duration of firm-customer relationship is a significant predictor of switching behaviour. Specifically, the longer a respondent's relationship with a service provider, the less likely he/she is to switch. This implies that the longer a service provider is able to keep relationship with customers by satisfying them and meeting their needs and requirements, the less likely will such customers completely switch to competitors, even with the introduction of MNP in some MTIs in developing countries. 
These findings confirm previous ones that when service providers are able to keep profitable customers longer in business relationships by meeting their needs and expectations, the more the customers are likely to become active users of the firm's services (Roos \& Gustafsson, 2011), feel committed to current service provider (Bansal et al., 2004), and therefore, will be less likely to switch to new service providers (e.g. Bell et al., 2005; Chiu et al., 2005).

Third, this study found that the strongest predictor of switching behaviour is non-porting behaviour. In the logistic regression results, it was found that porting behaviour negatively affected full switching behaviour (reduces the likelihood of full switching). This implies that respondents who ported their mobile number(s) were less likely to fully switch to other competitor mobile network than those who do not port their mobile number (non-porters). These findings imply that porting of mobile number may not necessarily be a significant factor that influence consumers' decision to completely switch to new service providers. This is because through the MNP platform consumers are able to enjoy other service providers' services while maintaining the current service provider. Therefore, they may not want to switch entirely in order to benefit from competitor service providers and still keep their mobile numbers with other important people.

This finding lends support to Kim et al. (2003) who found that switching cost like switching number (porting one's mobile number) is considered as a formation factor of an important subscriber loyalty, preventing subscriber from churning for other carriers. The results also show that non-porters, rather, are more likely to switch totally or completely to other competitors. This implies that MNP appears to be effective in inducing partial switching behaviour but not necessarily complete or total switching behaviour, especially among adopters of MNP in GMTI. This has implication for market segmentation and targeting strategy by attracting non-adopters of MNP to completely switch to new service providers, using attractive offers (Bansal et al., 2005; Hsieh et al., 2012).

Fourth, income was found to be the fourth most important predictor of switching behaviour. We can conclude that the likelihood of a higher income respondent switching is higher than a lower income respondent, all other factors held constant. Our finding on income is consistent with those of previous studies done in similar mobile telecom service context (e.g., Dholakia \& Uusitalo, 2002; Keaveney, \& Parthasarathy, 2001; Ranganathan et al., 2006), while it contradicts those of Effah-Bediako et al. (2013) whose study was limited to a small number of college students in one region of Ghana.

Fifth, the present study found that religiosity of mobile subscribers did not have significant influence on switching behaviour, contradicting some previous studies (e.g., Choi, 2010; Choi et al., 2013). In particular, religiosity was not found to be significant predictor of actual switching, which contradicts the findings of Choi (2010) and Choi et al. (2013) who found that religion and religiosity are strong factors that determine consumer switching in Korea and other Asian countries. One possible reason might be that religiosity affects other switching behaviour such as porting and switching intentions but not a complete or total switching behaviour in GMTI.

Sixth, this study did not find some consumer background characteristics such as gender, education, marital and phone use experience to be significant factors in determining actual consumer switching among mobile subscribers in GMTI. The finding on gender lends support to those of Shin and Kim (2008) who found that gender may not affect subscribers' decisions on switching, but contradicts others studies such as Ranganathan et al. (2006) and Effah-Bediako et al. (2013) who found that males are more prone to switching carriers. The reason could be that in Effah-Bediako et al.'s (2013) study the sample involved only students of one higher education institution, smaller than those used in this study, who have varied background characteristics. Moreover, while our finding on education confirms those of Effa-Bediako et al. (2013), it is inconsistent with many others in similar service context (e.g. Dholakia \& Uusitalo, 2002; Keaveney \& Parthasarathy, 2001; Shin \& Kim; 2008; Ranganathan et al., 2006).

From the above discussion, this study has empirically proven that since customer characteristics are different from one industry and country contexts to the other, it is critically important for marketing managers in general and mobile telecom managers in particular to conduct empirical studies in their CSB and background characteristics influence such switching decisions. The findings of the study also imply that, in GMTI, some of the important demographic predictors of actual switching behaviour include age, income, porting behaviour and relationship length with firm. These variables could serve as important criteria for marketing segmentation purposes among mobile subscribers in the mobile voice market in GMTI. 


\subsection{Theoretical Contribution}

The present study makes a major contribution to the field of marketing by assessing the extent to which consumer background characteristics such as demographic, religiosity and porting behaviour contribute to predicting mobile subscribers' switching behaviour in MTI, from a developing country perspective. This is in response to the call for more research into the effect of demography and religious factors on CSB due to empirical inconsistencies in previous CSB research in general and relatively little research attention in this area in developing country mobile markets in particular, as pointed out in the literature review and discussion chapters. Therefore, this study extends knowledge on the contribution of demographic and religious factors as predictors of CSB in MTI. It draws the attention of scholars, practitioners and researchers to the importance of demographic variables in the consumer switching decision, and for the purposes of marketing segmentation.

Generally, the present study found that consumer demography and religious background characteristics can influence their switching behaviour. Specifically, four variables, age, income, porting behaviour, relationship length with firm significantly contributed to predicting actual switching behaviour in GMTI, confirming many past research (e.g. Shin \& Kim, 2008; Dholakia \& Uusitalo, 2002; Keaveney, \& Parthasarathy, 2001; Ranganathan et al., 2006). Among these, porting behaviour contributed the most to predicting switching behaviour $(63 \%)$, followed by age (27\%), length of firm-customer relationship $(25 \%)$ and monthly income $(24 \%)$.

Moreover, the findings indicate that five factors, which are gender, education, marital status and religiosity and experience in phone use are not significant predictors of switching behaviour in GMTI. In particular, religiosity was not found to be significant predictor of total switching, which contradicts the findings of Choi (2010) and Choi et al. (2013) who found that religion and religiosity are strong factors that determine consumer switching in Korea and other Asian countries. Thus, this study has contributed to the debate on the relative effect of demographic and religious variables as predictors of switching behaviour of mobile subscribers in developing countries. It has drawn the attention of scholars, practitioners and researchers to the importance of demographic variables in the consumer switching decision.

\subsection{Managerial Contribution}

The findings imply that, in GMTI, some of the important consumer characteristics such as age, income, porting behaviour, relationship length with firm could serve as important criteria for marketing segmentation and targeting purposes. Mobile network operators can segment mobile subscribers into older and younger age groups, low and high income groups, adopters and non-adopters of MNP groups, older and newer subscriber groups, and tailor well-co-ordinated marketing programmes to effectively meet their unique needs and life situations. In this regard, different service offerings may be targeted at young and old mobile subscribers, low and high income groups, porters and non-porters, and new and old customers. These service offerings should be tailored with the intent of inducing targeted consumer groups to stay and not switch.

For competitor service providers, the findings provide implications for attracting consumer groups that are more vulnerable to switching, especially in developing countries. Competitors can develop attractive and exciting service offerings to entice particular consumer groups that are more likely to switch. In particular, attractive competitor offering can induce switching among younger mobile subscribers, higher income earners, new mobile subscribers of competitor networks, and non-adopters of MNP.

\section{Limitations and Future Research}

The study is limited in terms of context and variables included. First, since the findings are based on data from Ghana only, which places some limitation on the generalizability of the findings to all developing countries. Future research could replicate the study in other developing countries and compare the results with those in this study to improve upon the generalizability of the findings. Second, in this study many demographic variables as well as cultural factors were not included in the research model. Future research should be extended to include such variables in order to enhance our understanding of the role of consumer background characteristics in predicting mobile subscribers' switching behaviour.

\section{Conclusion}

The main purpose of this study was to assess the extent to which consumer demography, religiosity and porting behaviour combine to predict mobile subscribers' switching behaviour from an emerging market perspective. The results of the logistics regression model indicate that the combined effect of demography, religiosity and porting behaviour has significant effect on mobile subscribers' switching behaviour. The findings highlights the importance of demographic variables such as age, income, length of relationship and porting behaviour in 
influencing switching behaviour. Apart from confirming some existing literature and contradicting others, the results also reveal new findings on the influence of relationship length and porting behaviour on subscribers' switching behaviour. The present study has provided empirical evidence on the relative effect of demography and religiosity on consumer switching from a developing country perspective. The limitations of this study present avenues for future research.

\section{References}

Anderson, G. Jnr. (2013). Religion and Morality in Ghana: A Reflection. Global Journal of Arts Humanities and Social Sciences, 1(3), 162-170.

Bansal, H. S., Taylor, S. F., \& James, Y. (2005). "Migrating" to New Service Providers: Toward a Unifying Framework of Consumers' Switching Behaviors. Journal of the Academy of Marketing Science, 33(1), 96-115. http://dx.doi.org/10.1177/0092070304267928

Batra, R., Ahuvia, A., \& Bagozzi, P. R. (2012). Brand Love. Journal of Marketing, 76(2), 1-16. http://dx.doi.org/10.1509/jm.09.0339

Bell, S. J., Auh, S., \& Smalley, K. (2005). Customer relationship dynamics: Service quality and customerloyaltyin the context of varying levels of customer expertise and switching costs. Journal of the Academy of Marketing Science, 33, 169-183.

Buehler, S., \& Haucap, J. (2004). Mobile Numbering and Number Portability in Ireland. A report to the ODTR, Ovum: London. Journal of Industry, Competition and Trade, 4(3), 223-238.

Carroll, A. B., \& Ahuvia, C. A. (2006). Some antecedents and outcomes of brand love. Market Letter, 17, 79-89. http://dx.doi.org/10.1007/s11002-006-4219-2

Carroll, J., Howard, S., Peck, J., \& Murphy, J. (2002). A field study of perceptions and use of mobile telephones by 16-22 year olds. J. Inf. Technol. Theory Appl., 4(2), 49-62.

Chen, P. Y., \& Hitt, L. M. (2002). Measuring switching costs and the determinants of customer retention in Internet enabled businesses: A study of the online brokerage industry. Information Systems Research, 13(3), 255-274.

Chiu, H. C., Hsieh, Y. C., Li, Y. C., \& Lee, M. (2005). Relationship marketing and consumer switching behavior. Journal of Business Research, 58, 1681-1689.

Choi, Y. (2010). Religion, religiosity, and South Korean consumer switching behaviors. Journal of Consumer Behaviour, 9(3), 157-171. http://dx.doi.org/10.1002/cb.292

Choi, Y., Paulraj A., \& Shin J. (2013). Religion or Religiosity: Which Is the Culprit for Consumer Switching Behavior? Journal of International Consumer Marketing, 25(4), 262-280. http://dx.doi.org/10.1080/08961530.2013.803901

Clemes, M. D., Gan, C., \& Zheng, L. Y. (2007). Customer switching behaviour in the New Zealand banking industry. Banks and Bank Systems, 2(4), 50-65.

Dholakia, R. R., \& Uusitalo, O. (2002). Switching to electronic stores: Consumer characteristics and the perception of shopping benefits. International Journal of Retail \& Distribution Management, 30(10), 459-469. http://dx.doi.org/10.1108/09590550210445335

Effah-Bediako, D., Deh I. Y., \& Asuamah, S. Y. (2013). Demographic Effect in the Switching Decisions of Mobile Service Users, International Journal of Innovative Research and Development, 2(8), 422-429.

Gilbert D, Lee-Kelley, L., \& Barton, M. (2003). Technophobia, gender influences and consumer decision making for technology related products. European Journal of Innovation Management, 6(3/4), 253-263.

Global Index of Religiosity and Atheism. (2012). Retrieved on 27 December 2014 from http://www.wingia.com/web/files/news/14/file/14.pdf

Hair, J. F., Black, W. C., Babin, B. J., \& Anderson, R. E. (2010). Multivariate Data Analysis. Englewood Cliffs, NJ: Prentice Hall.

Hou, A. C. Y., Chern, C. C., Chen, H. G., \& Chen, Y. C. (2011). Migrating to a New Virtual World: Exploring MMPORG Switching through Human Migration Theory. Computers in Human Behavior, 27(5), 1892-1903. http://dx.doi.org/10.1016/j.chb.2011.04.013

Hsieh, J. K., Hsieh, Y. C., Chiu, H. C., \& Feng, Y. C. (2012). Post-Adoption Switching Behavior for Online Service Substitutes: A Perspective of the Push-Pull-Mooring Framework. Computers in Human Behavior, 
28, 1912-1920.

Keaveney, S. M. (1995). Customer switching behavior in service industries: An exploratory study. Journal of Marketing, 50(2), 71-82.

Keaveney, S. M., \& Parthasarathy, M. (2001). Customer switching behavior in online services: an exploratory study of the role of selected attitudinal, behavioral, and demographic factors. Journal of the Academy of Marketing Science, 29(4), 374-390.

Kim, M., Kliger, D., \& Vale, B. (2003). Estimating switching costs: The case of banking. Journal of Financial Intermediation, 12(1), 25-56.

Kotler, P., \& Keller, K. L. (2012). Marketing Management (14th ed.). Upper Saddle River, NJ: Prentice Hall.

Kuada, J. (2010). Culture and leadership in Africa: a conceptual model and research agenda. African Journal of Economic and Management Studies, 1(1), 9-24.

Lee, J., Kim, Y., Lee, J. D., \& Park, Y. (2006). Estimating the extent of potential competition in the Korean mobile telecommunications market: Switching costs and number portability. International Journal of Industrial Organization, 24(1), 107-124.

Lopez J. P. M., Redondo Y. P., \& Olivan, F. J. S. (2006). The impact of customer relationship characteristics on customer switching behaviour. Difference between switchers and stayers, Managing Service Quality, 16(6), 556-574.

Moschis, G. P., \& Ong, F. S. (2011). Religiosity and consumer behavior of older adults: A study of subcultural influences in Malaysia. Journal of Consumer Behaviour, 10(1), 8-17.

Nimako, S. G. (2012). Towards a Comprehensive Definition and Typology of Consumer Switching Behaviour: Unearthing research gaps. Research Journal of Social Science and Management, 2(3), 67-73.

Nimako, S.G., Ntim, B. A., \& Mensah, A. F. (2014). Effects of Mobile Number Portability Adoption on Consumer switching intentions. International Journal of Marketing Studies, 6(2), 117-134. http://dx.doi.org/10.5539/ijms.v6n2p117

Njite, D., Kim, W. G., \& Kim, L. H. (2008). Theorizing Consumer Switching Behavior: A General Systems Theory Approach. Journal of Quality Assurance in Hospitality \& Tourism, 9(3), 185-217.

Ranganathan, C., Seo, D., \& Babad, Y. (2006). Switching behavior of mobile users: Do users' relationalinvestments and demographics matter? European Journal of Information Systems, 15(3), 269-276.

Sheth, J. N., \& Parvatiyar, A. (1995). Relationship marketing in consumer markets: Antecedents and consequences. Journal of the Academy of Marketing Science, 23(4), 255-271.

Shin, D. H., \& Kim, W. Y. (2007). Mobile number portability on customer switching behavior: In the case of the Korean mobile market. Info, 9(4), 38-54.

Shin, D. H., \& Kim, W. Y. (2008). Forecasting customer switching intention in mobile service: An exploratory study of predictive factors in mobile number portability. Technological Forecasting and Social Change, 75(6), 854-874.

Yamane, T. (1967). Statistics: An introductory analysis. New York: Harper and Row.

Ye, C., \& Potter, R. (2011). The Role of Habit in Post-Adoption Switching of Personal Information Technologies: An Empirical Investigation. Communications of the Association for Information Systems, 28(1), 585-610.

Yousaf, S., \& Malik, M. S. (2013). Evaluating the influences of religiosity and product involvement level on the consumers. Journal of Islamic Marketing, 4(2), 163-186. http://dx.doi.org/10.1108/17590831311329296

Zhang, K. Z. K., Cheung, C. M. K., \& Lee, M. K. O. (2012). Online service switching behavior: The case of blog service providers. Journal of Electronic Commerce Research, 13(3), 184-197.

\section{Copyrights}

Copyright for this article is retained by the author(s), with first publication rights granted to the journal.

This is an open-access article distributed under the terms and conditions of the Creative Commons Attribution license (http://creativecommons.org/licenses/by/3.0/). 